\title{
MOLECULAR DOCKING STUDIES OF ISOLATED COMPOUNDS ANDROGRAPHOLIDE AND BETULIN FROM METHANOLIC LEAVES EXTRACT OF ANDROGRAPHIS ECHIOIDES AS ALPHA- AMYLASE AND ALPHA-GLUCOSIDASE ACTIVATORS
}

\section{S. GURUPRIYA* ${ }^{*}$ L. CATHRINE ${ }^{1}$}

${ }^{*}$ Department of Chemistry, Holy Cross College (Autonomous) Affiliated to Bharathidasan University, Tiruchirappalli 620002, Tamil Nadu, India "Email: gurupriyaonline@gmail.com

Received: 04 Sep 2020, Revised and Accepted: 08 Mar 2021

ABSTRACT

Objective: The purpose of this study is to isolate and characterize the andrographolide and betulin from methanolic leaves extract of Andrographis echioides and also used to evaluate the alpha-amylase and alpha-glucosidase inhibitory activity of isolated compounds using in silico docking studies.

Methods: The isolation was done using column chromatography using gradient mobile phase. Structural elucidation was carried out on the basis of spectral analysis. In this view, andrographolide and betulin were prepared for the docking evaluation. In silico docking studies were carried out using a recent version of Auto Dock 4.2, which has the basic principle of Lamarckian genetic algorithm.

Results: On the basis of the spectral data, the compounds have been established as andrographolide and betulin are being reported from this plant for the first time. The result showed that the andrographolide showed a binding affinity for amylase: $(-7.9 \mathrm{kcal} / \mathrm{mol})$ and for glucosidase $(-7.2$ $\mathrm{kcal} / \mathrm{mol})$ while betulin showed $(-8.6 \mathrm{kcal} / \mathrm{mol})$ and $(-5.2 \mathrm{kcal} / \mathrm{mol})$, respectively.

Conclusion: Therefore, it is suggested that isolated compounds andrographolide and betulin contributed excellent $\alpha$-amylase and $\alpha$-glucosidase inhibitory activity because of its structural parameters. Thus, these isolated compounds can be effectively used as drugs for treating diabetes which is predicted on the basis of docking scores.

Keywords: Andrographolide, Betulin, Binding energy, Andrographis echioides, Leaves

(C) 2021 The Authors. Published by Innovare Academic Sciences Pvt Ltd. This is an open access article under the CC BY license (https://creativecommons.org/licenses/by/4.0/) DOI: https://dx.doi.org/10.22159/ijap.2021v13i3.39641. Journal homepage: https://innovareacademics.in/journals/index.php/ijap

\section{INTRODUCTION}

Diabetes mellitus is a chronic metabolic disorder and it also affects the metabolism of carbohydrates, protein and fat. The main reason is the production of low amount of insulin by the pancreas [1]. Type I diabetes occur due to low amount of insulin production by $\boldsymbol{\beta}$-cells, while type II diabetes occur due to $\boldsymbol{\beta}$-cell dysfunction [2]. The enzymes alpha-glucosidase are responsible for the breakdown of oligo-and disaccharides to monosaccharides. $\alpha$-amylase and $\alpha$ glucosidase inhibitors is useful for lowering the process of glucose absorption and decreases glucose level in blood [3]. Diabetes mellitus patients suffer with high level of sugar in blood, unusual thirst, frequent urination, extreme hunger and loss of weight, blurred vision, nausea and vomiting, extreme weakness and irritability, tiredness and mood change [4]. Inhibitors of amylase and ? glucosidase responsible for the high amount of glucose in the blood [5]. Now day's herbal medicines are more effective than synthetic medicines. There is no side effect while using herbal medicine [6]. In silico studies are computer-oriented programming analysis which predicts, with reasonable accuracy, the results that are expected from actual experimental measurements in less time and much lower cost. Such studies are used to enhance our understanding of biological processes and protein-ligand interactions. In recent years, computer-aided studies are widely used in pharmaceutical industries in the drug discovery exercise to identify or optimize lead compounds with significant activity against biological receptors.

Andrographis echioides is belonging to the family of Acanthaceae and its tamil name is Gopuramthangi [7]. It is an ayurvedic herb plant used in the treatment of many ailments such as anti-inflammatory, anti-arthritic, antimicrobial, anti-ulcer, anti-oxidant activity, hair problems, etc., [8]. Their phytochemical constituents like flavonoids, tannins, phenol, glycosides, terpenoids, saponins, steroids, etc., [9]. Some anti-diabetic plants have been reported to possess triterpenes as their bioactive principles [10, 11]. Terpenoid, andrographolidelipoeic acid conjugate has demonstrated that hypoglycemic potentials [12]. The anti-hyperglycemic action of andrographolide was investigated in streptozotocin-induced diabetic rats. Oral treatment of andrographolide decreased the plasma glucose concentration of streptozotocin-diabetic rats in a dose-dependent manner. Similar treatment with andrographolide also decreased the plasma glucose in normal rats [13]. Numerous studies have demonstrated that the betulin is a lupane-type compound, characterised by isopropylidene group and five-membered ring and elicits a broad range of biological and pharmacological properties, including antifungal, antibacterial and antiviral activities [14]. The molecular docking methods were developed with a purpose of acquiring a large amount of compounds are docked against one target molecule and also used for the detection of new lead compounds or to reproduce an experimental conformation at elevated accuracy for the justification with experimental data [15]. Therefore, in the present study is to predict the in silico evaluation of $\alpha$-amylase and $\alpha$-glucosidase inhibitory activity and the stereochemistry binding of the isolated compound andrographolide and betulin on $\alpha$-amylase and $\alpha$-glucosidase has been carried out, which may helpful in the development of potent $\alpha$-amylase and $\alpha$ glucosidase inhibitors.

\section{MATERIALS AND METHODS}

\section{Collection of plant material}

The leaves of Andrographis echioides were collected in the month of May from the Mullipatti, Pudukkottai, Tamil Nadu, India. The plant was identified and leaves of Andrographis echioides were authenticated and confirmed from Dr. S. John Britto, Director, Rapinat herbarium, St. Joseph College, Tiruchirappalli, and Tamil Nadu for identifying the plants. The voucher specimen number SGP001 (7.06.2017).

\section{Preparation of methanolic extract}

The methanol extracts were prepared by soaking $1.5 \mathrm{~kg}$ of the dried powder plant materials in $3 \mathrm{~L}$ of methanol by using a soxhlet extractor for $10 \mathrm{hr}$ continuously. The extracts were filtered through Whatman filter paper No. $42(125 \mathrm{~mm})$. The filtered extract was 
concentrated and dried by using a rotary evaporator under reduced pressure. The final dried samples (998 g) were stored in labeled sterile bottles and kept at $-20^{\circ} \mathrm{C}[16]$.

\section{Isolation of phytochemical compounds by column chromatography}

The condensed methanolic extract of leaves (998 g) of the sample was subjected to column chromatography over TLC grade silica gel. The preparation of solvent systems used to obtain andrographolide $(154 \mathrm{mg} / 998 \mathrm{~g})$ ethyl acetate: methanol $(70: 30 \mathrm{v} \backslash \mathrm{v})$ from fractions 15 and betulin $(578 \mathrm{mg} / 998 \mathrm{~g})$ ethyl acetate: methanol $(80: 20 \mathrm{v} \backslash \mathrm{v})$ from fractions 13. The isolated compounds were detected on TLC plates by spraying with Libermann-Burchard reagent and heated at $100^{\circ} \mathrm{C}$ for $10 \mathrm{~min}$ [17].

Purification of isolated compounds by High-performance liquid chromatography

The analytical HPLC system (Shimadzu) was equipped with a diode array detector, a $20 \mu \mathrm{l}$ loop, 200 x $4.6 \mathrm{~mm}$ C18 column, methanol (HPLC grade, $0.2 \mathrm{~mm}$ filtered) used as a mobile phase. The isolated Andrographolide compounds were separated using a mobile phase of chloroform: methanol $(70: 30 \mathrm{v} / \mathrm{v})$ at a flow rate of $1.0 \mathrm{ml} / \mathrm{min}$, column temperature $30^{\circ} \mathrm{C}$. Injection volume was $40 \mu \mathrm{l}$ and detection was carried out at $346 \mathrm{~nm}$. The isolated betulin compounds were separated using a mobile phase of n-hexane: ethyl acetate (8:2 v/v) [18].

\section{Structural elucidation study of isolated compound}

Different spectroscopic methods including UV, ${ }^{1} \mathrm{H}$ NMR, ${ }^{13} \mathrm{C}$ NMR were used to elucidate the structure of isolated compounds. The UVvisible spectrum of the isolated compounds in methanol was recorded using a Shimadzu $160 \mathrm{~A}$ UV-visible spectrophotometer. ${ }^{1} \mathrm{H}$ and ${ }^{13} \mathrm{C}$ NMR spectra were acquired on Bruker WP 200 SY and AM $200 \mathrm{SY}$ instruments $\left({ }^{1} \mathrm{H}, 200.13 \mathrm{MHz} ;{ }^{13} \mathrm{C}, 50.32 \mathrm{MHz}\right)$ using TMS as internal standard and $\mathrm{CDCL}_{3}$ as solvent. GC-MS analysis of the methanolic extract was performed using a Perkin-Elmer GC Clarus 500 system and Gas chromatograph interfaced to a Mass spectrometer (GC-MS) equipped with a Elite-I, fused silica capillary column (30 mmX0.25 mm 1D X $1 \mu \mathrm{Mdf}$, composed of 100\% Dimethyl polysiloxane) [19, 20].

Molecular docking studies on $\alpha$-amylase and $\alpha$-glucosidase inhibitory activity with andrographolide and betulin

To investigate the molecular association, three-dimensional structures of receptor and ligands have to be retrieved from the molecular graphics laboratory tools (MGL-1.5.6 version, Scripps Research Institute, Florida, FL, USA). In order to execute the docking, the protein and ligands were downloaded from the protein data bank and pubchem (http://www.rcsb.org/pdb). Preparation of protein and compounds were completed using dock prep in chimera (1.10.1 version UCSF Resources for biocomputing visualization and informatics, NIH, USA) and Compounds retrieved from pubchem database were optimized and converted to pdb format.

\section{Molecular docking}

Molecular docking analysis was carried out to predict the affinity between the two compounds, namely, betulin, andrographolide, against alpha-amylase and glucosidase using Auto Dock 4.2 program. Polar hydrogen atoms were individually added and merged to the protein structure. Kollman charges and solvation parameters were determined by default. For energy minimization, gasteigor charges were added along with rotatable and flexible bonds. Grid maps were assigned by co-crystallized ligands in the $\mathrm{x}, \mathrm{y}$ and z-dimensions of $20 \times 26 \times 20$ points were set to cover the active site of the protein. The Lamarckian Genetic Algorithm (LGA) was used to search for the lowest binding energy by implementing local minimization of the genetic algorithm to enable modification of the gene population. LGA parameters were set as follows: 100 search (docking) runs; population size of 150; 25,000,000 of energy evaluations; 27,000 numbers of generations; mutation rate of 0.02 and crossover rate of 0.8 . Docking calculation was performed in the Auto Dock software $4.2[21,22]$.

\section{RESULTS AND DISCUSSION}

Structural elucidation of isolated compounds andrographolide and betulin from methanolic leaves extract of Andrographis echioides

Structural Elucidation of isolated compound andrographolide from methanolic leaves extract of Andrographis echioides

The chemical name of andrographolide is $3 \alpha, 14,15,18$ tetrahydroxy-5 $\beta, 9 \beta \mathrm{H}, 10 \alpha$-labda-8, 12-dien-16-oic acid $\gamma$-lactone and its molecular formula and molecular weight are $\mathrm{C}_{20} \mathrm{H}_{30} \mathrm{O}_{5}$ and 350.4 (C $68.54 \%, \mathrm{H} 8.63 \%$, and $\mathrm{O} 22.83 \%$ ), respectively. The previous study suggested that the andrographolide is a major bioactive phytoconstituents found in various parts of Andrographis paniculata but particularly in the leaves [23].

The UV $\lambda_{\max }$ value of compound andrographolide was $257 \mathrm{~nm}$ (fig. 1).

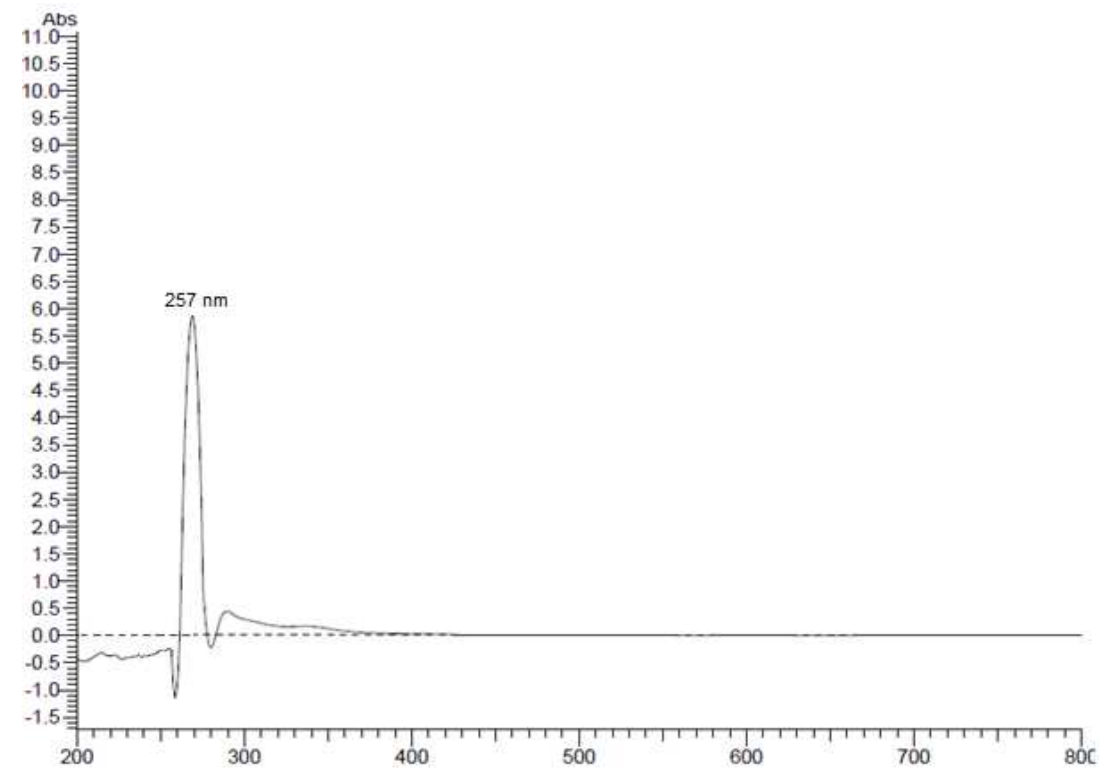

Fig. 1: UV spectra for isolated compound andrographolide,

In the proton ${ }^{1} \mathrm{H}$ NMR spectra of andrographolide (fig. 2$)$ showed $\delta 6.62(1 \mathrm{H}, \mathrm{t}, \mathrm{C12}), 4.90(1 \mathrm{H}, \mathrm{d}, \mathrm{C14}), 4-15-4.40(2 \mathrm{H}, \mathrm{m}, \mathrm{C}-15), 2.492-2.499$ $(5 \mathrm{H}, \mathrm{m}, \mathrm{C} 2, \mathrm{C} 7, \mathrm{C} 9), 0.65\left(2 \mathrm{XCH}_{3}, \mathrm{~s}, \mathrm{C18}, \mathrm{C20}\right)$ 


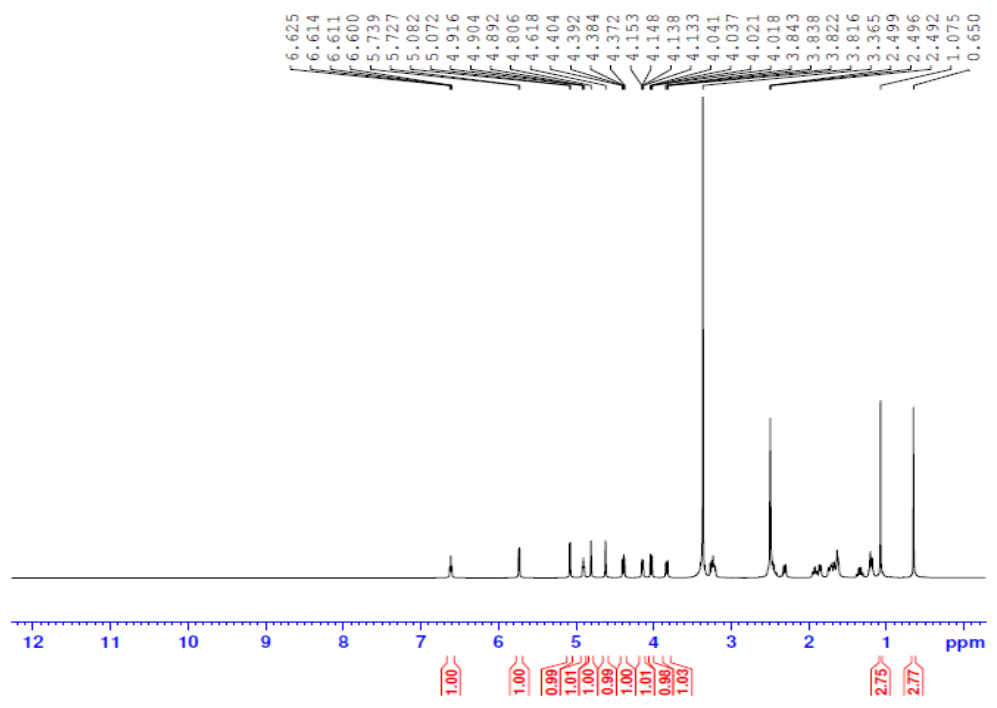

Fig. 2: ${ }^{1} \mathrm{H}-\mathrm{NMR}$ spectra for isolated compound andrographolide,

In the ${ }^{13} \mathrm{C}$ NMR spectra of andrographolide (fig. 3) showed 39.6 (C1), 28.3 (C2), 78.8 (C3), 40.2 (C4), 55.9 (C5), 24.42 (C6), 39.60 (C7), 148.0 (C8), 55.93 (C9), 39.60 (C10), 24.4 (C11), 146.8 (C12), 129.4 (C13), 64.9 (C14), 74.8 (C15), 170.4 (C16), 108.7 (C17), 23.5 (C18), 64.9 (C19), $15.2(\mathrm{C20})$

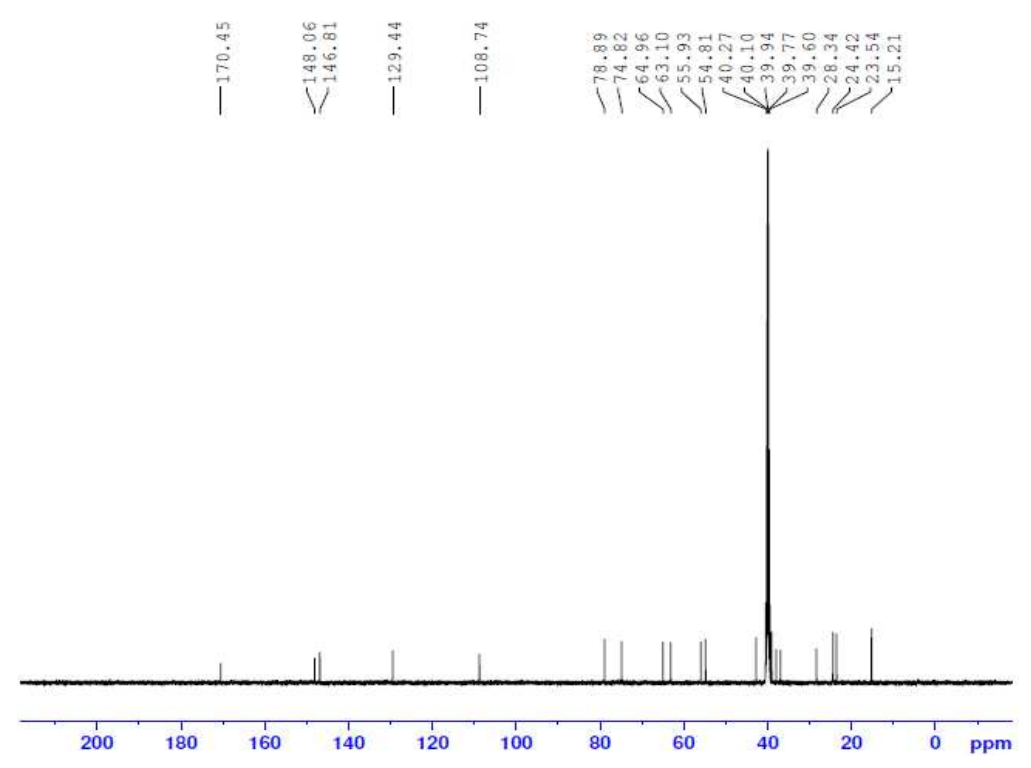

Fig. 3: ${ }^{13} \mathrm{C}$-NMR spectra for isolated compound andrographolide

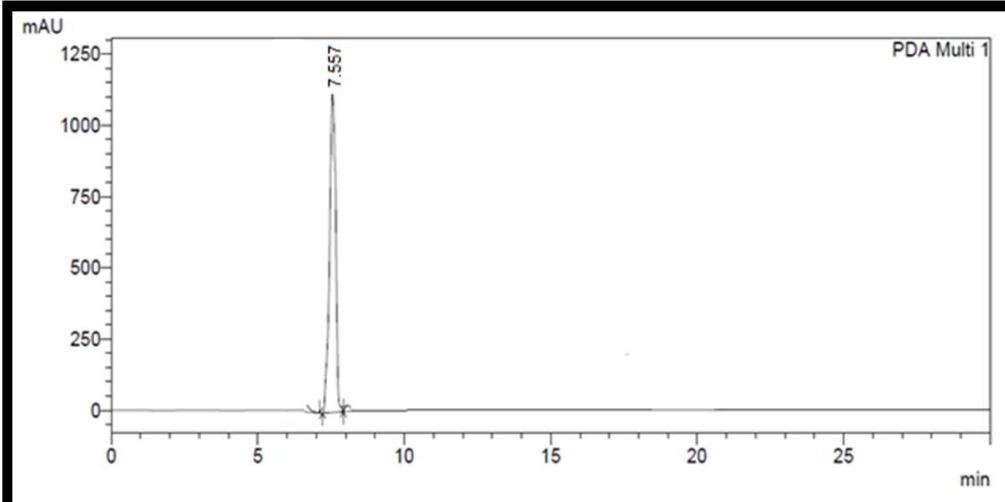

Fig. 4: HPLC spectra for isolated compound andrographolide 
The isolated compound obtained is colourless solid with melting point range of $228{ }^{\circ} \mathrm{C}-238^{\circ} \mathrm{C}$. This was further supported by ${ }^{13} \mathrm{C}$ NMR spectral analysis, which displayed 20 signals for all carbon atoms in the molecule, including one carboxyl, four methyl's, eight non-protonated carbons, two methylene's, three methane's, one cyclic alkene, and one benzylic carbon atom. This corresponds to a similar report by (Koteswara Rao et al., 2004) [24], suggesting the isomer to be similar to andrographolide $\left(\mathrm{C}_{20} \mathrm{H}_{30} \mathrm{O}_{5}\right)$. However, the $1 \mathrm{H}$ NMR spectrum had several signals comparable to that of $13 \mathrm{C}$ NMR of the isolated compound Viz are methylene signalling at ( $\delta$ $6.62, \mathrm{t})$, cyclic alkene $(\delta 4.90, \mathrm{~s})$ and carboxyl $(\delta 4.40, \mathrm{~s})$. Thus, the strong similarities to andrographolide as described by (Du et al., 2003) [25].

\section{Purification of an isolated compound by HPLC}

The Retension time of andrographolide isolated from the methanolic Leaves extract of Andrographis echioides was about 7.557 was shown by HPLC peak (fig. 4).

Mass spectrum of isolated compound andrographolide showed parent molecular ion $\left[\mathrm{M}^{+}\right]$peak at $\mathrm{mlz} 350.4 \mathrm{~g} / \mathrm{mol}$, which corresponds to the molecular formula $\mathrm{C}_{20} \mathrm{H}_{30} \mathrm{O}_{5}$. The GCMS spectra of these isolated compounds revealed the characteristic fragments $\mathrm{m} / \mathrm{z}$ with $\%$ abundance $350.65,301.17,283.30,272.19,256.27,254.27$, $240.09,229.95,214.00,211.98,199.99,186.05,171.98,159.91$ $145.86,133.80,117.72,105.65,91.56,81.5,79.51,71.49,67.41$. The molecular weight and fragmentation pattern indicate that the compounds presenting andrographolide, respectively (fig. 5).

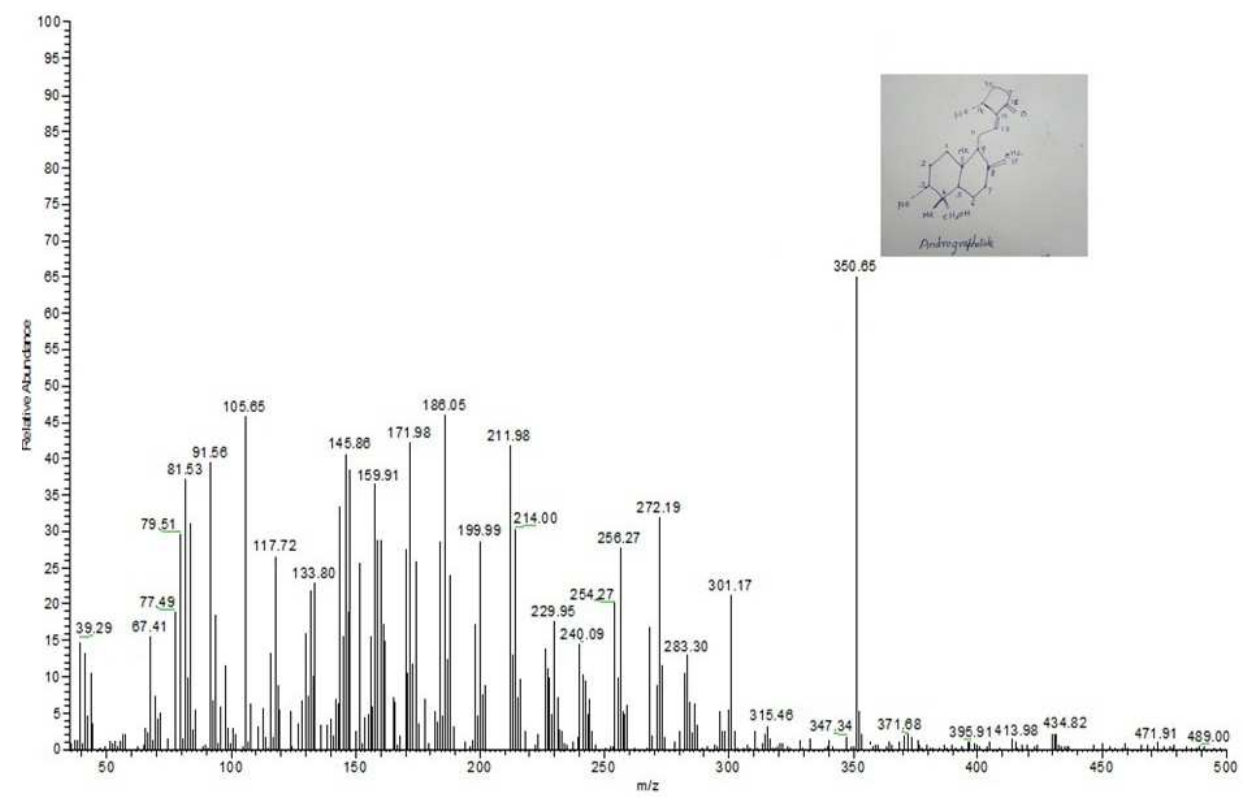

Fig. 5: Mass spectra for the isolated compound andrographolide

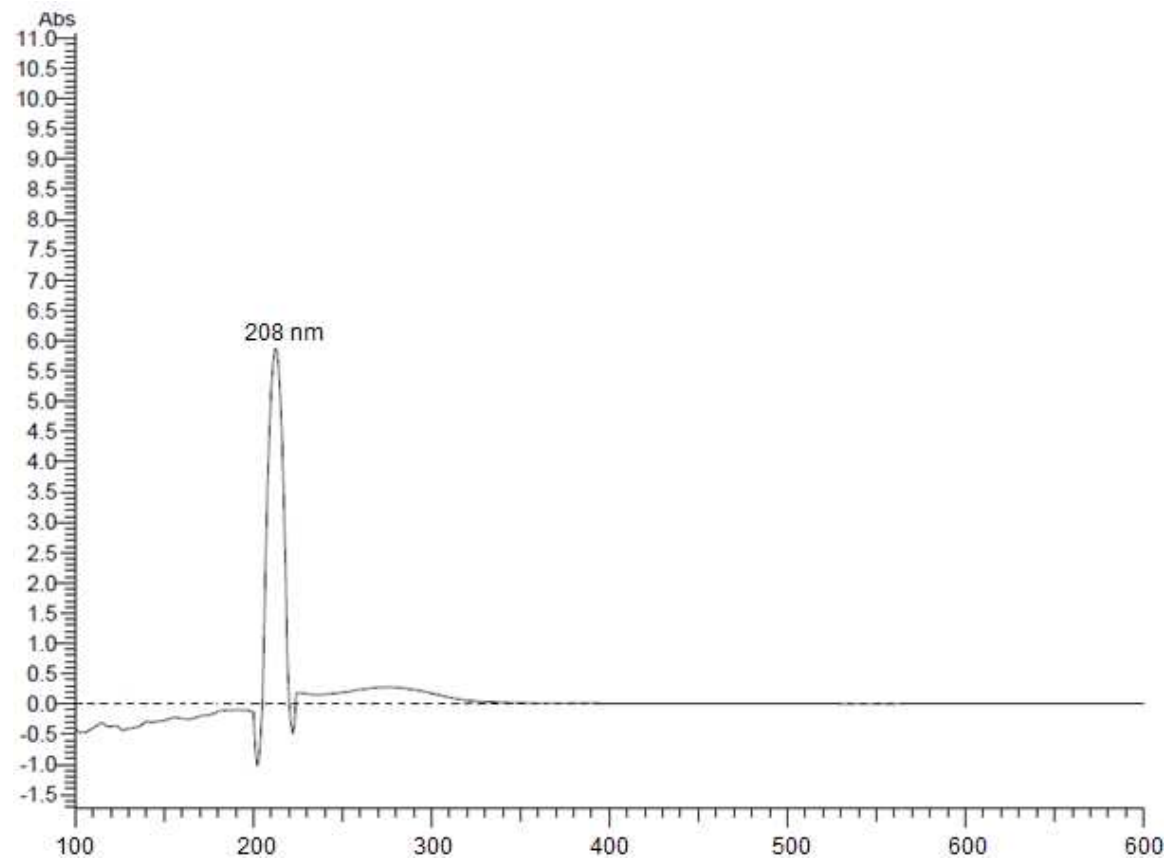

Fig. 6: UV spectra for isolated compound betulin,

In the proton ${ }^{1} \mathrm{H}$ NMR spectra of betulin (fig. 7) showed $\delta 4.70(1 \mathrm{H}, \mathrm{d}, \mathrm{H}-29 \mathrm{~b}), 4.58(1 \mathrm{H}, \mathrm{d}, \mathrm{H}-29 \mathrm{a}), 3.79(1 \mathrm{H}, \mathrm{d}, J=10.8, \mathrm{H}-28 \mathrm{~b}), 3.33(1 \mathrm{H}, \mathrm{d}, J$ $=10.8, \mathrm{H}-28 \mathrm{a}), 3.18(1 \mathrm{H}, \mathrm{dd}, J=5.3, \mathrm{H}-3 \alpha$ ), 1.67 (3H, s, H-30), 0.99 (3H, s, H-27), 0.97 (3H, s, H-26), 0.96 (3H, s, H-23), 0.80 (3H, s, H-25), 0.75 $(3 \mathrm{H}, \mathrm{s}, \mathrm{H}-24)$ 


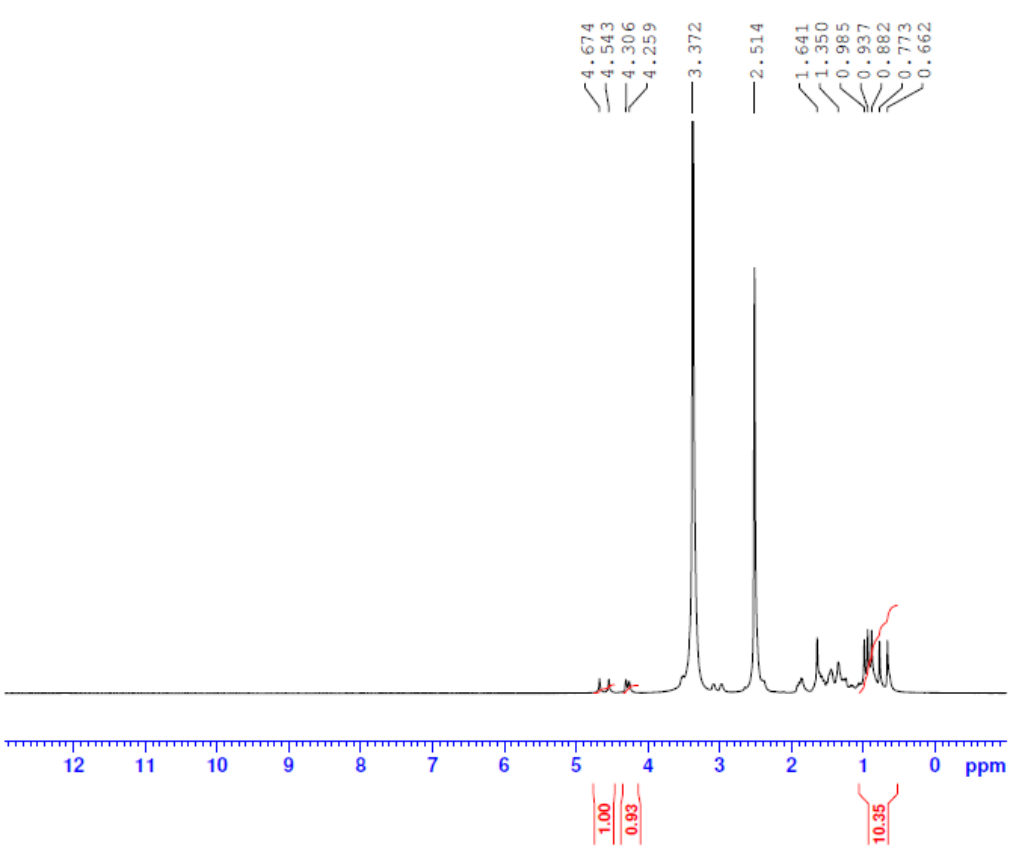

Fig. 7: ${ }^{1} \mathrm{H}-\mathrm{NMR}$ for isolated compound betulin,

In the ${ }^{13} \mathrm{C}$ NMR spectrum of betulin (fig. 8) showed $\delta 150.25$ (C-20),109.42 (C-29), 79.02 (C-3), 76.60 (C-28), 55.29 (C-5), 50.43 (C-9), 48.29 (C-19), 48.29 (C-17),48.00 (C-18), 42.84 (C-14), 40.83 (C-8), 40.01 (C-1), 38.70 (C-4), 38.04 (C-10), 37.17 (C-13),35.56 (C-7), 34.29 (C-22), 29.83 (C-21), 29.83 (C-16), 27.99 (C-23), 27.99 (C-2), 27.44 (C-15),25.10 (C-12), 20.93 (C-11), 19.31 (C-30), 18.32 (C-6), 16.13 (C-25), 15.98 (C-26), 15.38 (C-24),14.55 (C-27)

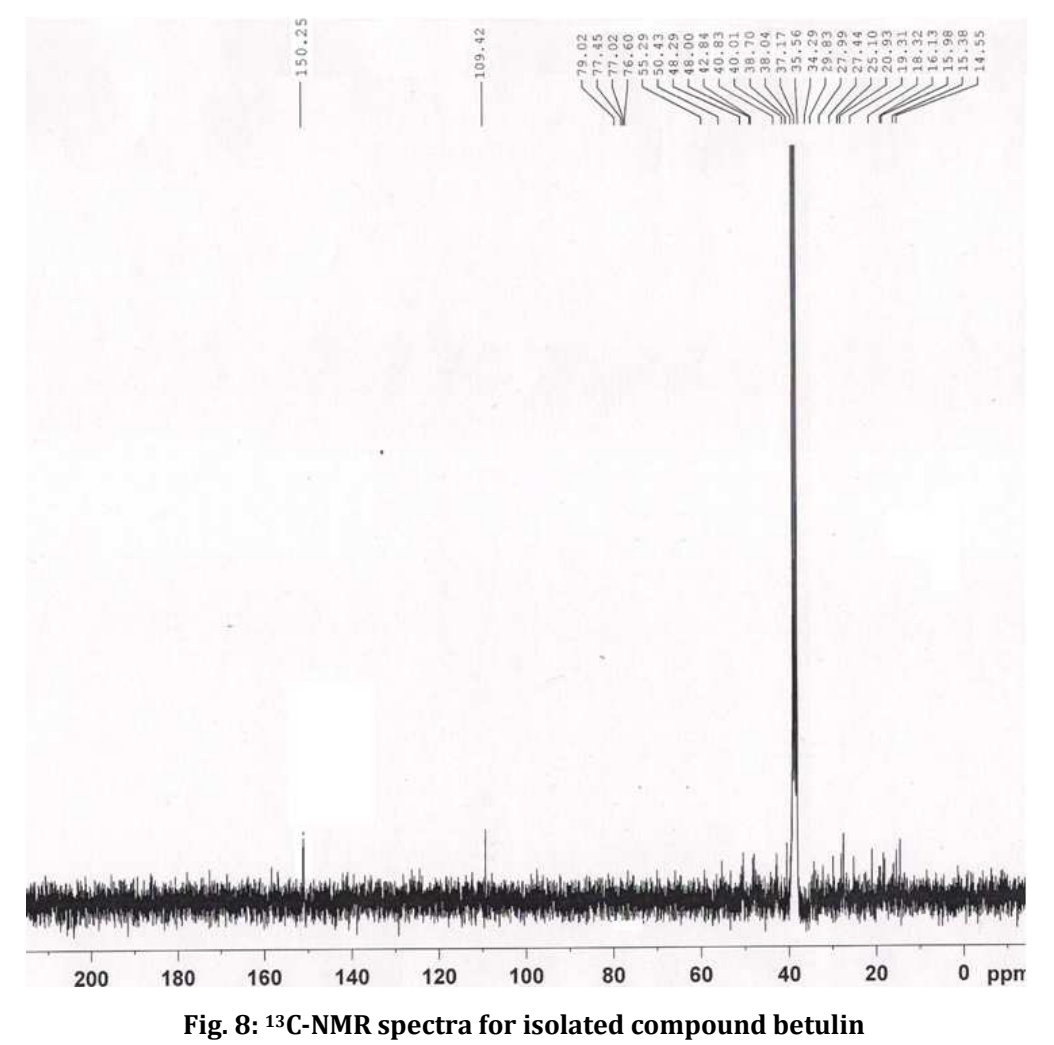

The $1 \mathrm{H}$ NMR shows the presence of a doublet of doublets was present at $\delta 3.372 \mathrm{ppm}$, which is characteristic of an $\alpha$-oriented hydrogen at $\mathrm{C}-3$ of a $3 \beta$-hydroxy triterpene. Doublets for geminal protons at $\delta 4.674$ and $4.543 \mathrm{ppm}$, along with the methyl group at $\delta$ $1.641 \mathrm{ppm}$, suggests that 1 was a lupeol-type triterpene derivative. Another pair of doublets at $\delta 3.37$ and $2.514 \mathrm{ppm}$, rather than a seventh methyl singlet around $\delta 0.882 \mathrm{ppm}$, confirms the presence of a second hydroxyl group at $\mathrm{C}-28$. The ${ }^{13} \mathrm{C}$ NMR spectrum further established 1 as a lupeol-type triterpene derivative. The characteristic pair of sp2 carbons comprising the double bond of betulin was observed as shifts at $\delta 150.25$ and $109.42 \mathrm{ppm}$ [27]. Oxygenated carbon shifts for C-3 and C-28 were observed at $\delta 79.02$ 
and $55.29 \mathrm{ppm}$, respectively. In all, the spectra revealed a compound with six methyl groups, thirtycarbon atoms (which is equivalent to the total number of carbon atoms in triterpenoid), a lupene-type triterpenoidal nucleus with two hydroxyl groups at C-3 and C-28 (a lupeoltype triterpene). Consequently, the compound was determined to be the known structure, 20(29)-lupene-3, 28-diol, more commonly known as betulin. Experimental NMR data was compared to that reported in the literature [28].

\section{Purification of an isolated compound by HPLC}

The Retension time of betulin isolated from the methanolic leaves extract of Andrographis echioides was about 10.293 was shown by HPLC peak (fig. 9).

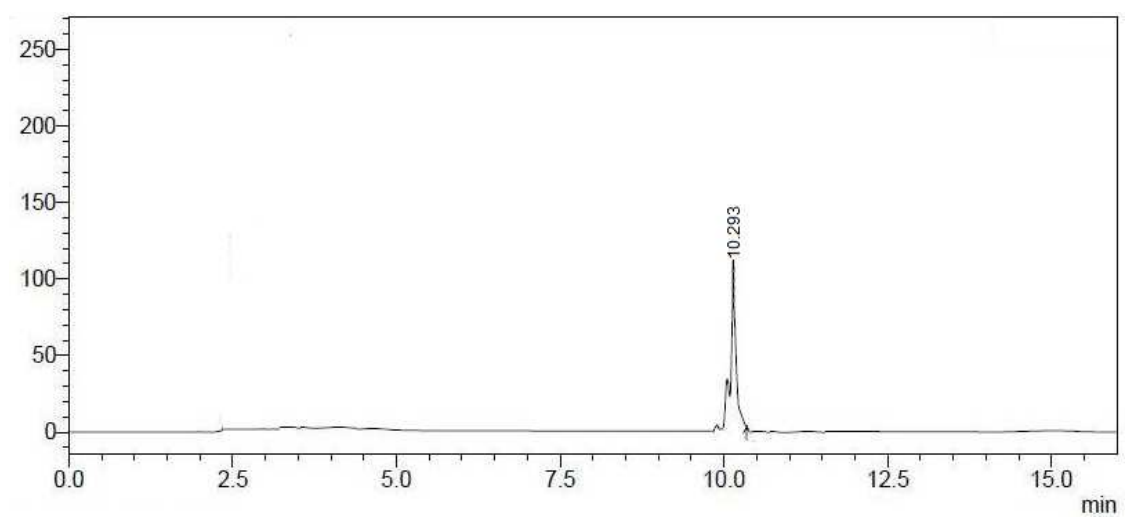

Fig. 9: HPLC spectra for isolated betulin

Mass spectrum of isolated compound betulin showed parent molecular ion $\left.\mathrm{M}^{+}\right]$peak at $\mathrm{mlz} 442.72 \mathrm{~g} / \mathrm{mol}$ which corresponds to the molecular formula $\mathrm{C}_{30} \mathrm{H}_{50} \mathrm{O}_{2}$. The GCMS spectra of these isolated compounds revealed the characteristic fragments $\mathrm{m} / \mathrm{z}$ with $\%$ abundance 441.96, 406.16, 401.32, 83.35, 358.28, 341.96, 327.96,
316.07, 281.86, 257.80, 255.87, 253.78, 231.84, 21.77, 209.83, $207.66,191.55,173.70,161.64,159.64,147.58,135.55,119.51$, 105.47, 91.42, 7.36, 47.23, 45.23. The molecular weight and fragmentation pattern indicate that the compounds presenting betulin respectively (fig. 10).

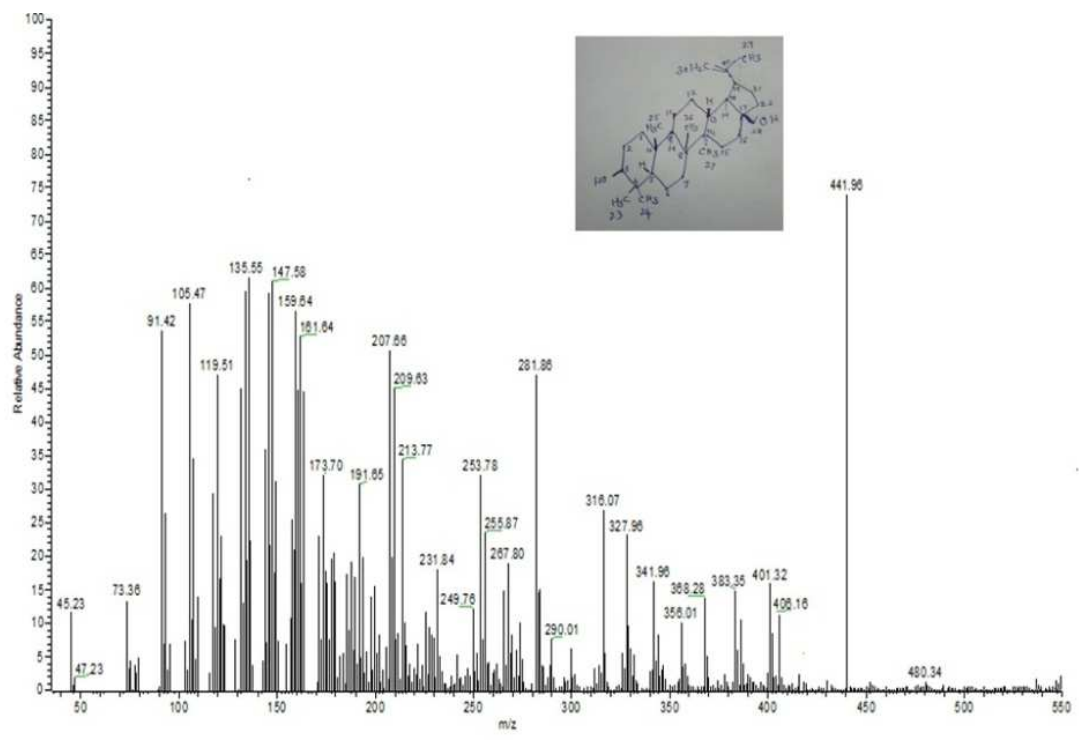

Fig. 10: Mass spectra for the isolated compound betulin

\section{Molecular docking analysis of isolated compounds andrographolide and betulin on alpha-amylase and alpha- glucosidase}

Docking of protein and small molecules is a method to distinguish the importance of atoms exchange. Major forces in molecular modeling and docking are hydrogen, hydrophobic and Vander waals interactions. In the primary analysis, active site or binding site identification is significant and challenging task. Basically, two methods are preferred in identifying active site; sequence similarity and co-crystallization. In recent era, there are many algorithms developed for probing active sites in particular protein structure and sequence. In this study, co-crystallized ligands were chosen to explore binding site.
In fig. 11, docked pose of $\alpha$-amylase enzyme with the andrographolide clearly demonstrated the binding positions of the ligand with the enzyme. The potential binding sites of the andrographolide (fig. 11a) was found to be TRP 58, GLN 62, THR 162, LEU 164, HIS 100, TYR 61, HIS 298, LEU 161, ASP 196, ALA 197, GLU 232, ARG 194, ASN 297, ASP 299, ILE 234. The potential binding sites of the betulin (fig. 11b) were found that TRY 150, THR 162, HIS 200, TRP 58, TYR 61, TRP 57, ASP 196, ARG 194, GLU 22, ALA 306, LYS 199. It proves that the ability of inhibiting the $\alpha$-amylase enzyme by the selected ligands.

In the (fig. 12) docked pose of $\alpha$-glucosidase enzyme with the andrographolide clearly demonstrated the binding positions of the ligand with the enzyme. The potential binding sites of the 
andrographolide (fig. 12a) was found to be LEU 678, PHE 649, ASP 616, HIS 674, TRP 61, ILE 441, LEU 405, MET 519, SER 676. The potential binding sites of the betulin (fig. 12b) was found that LEU 671, SER 676, TRP 376, PHE 649, TRP 481, PHE 525, LEU 678, ARG 411. It proves that the ability to inhibit the $\alpha$-glucosidase enzyme by the selected ligands.
Binding energy of the individual compounds was calculated by using the following formula, Binding energy $=A+B+C-D$ where $A$ denotes final intermolecular energy+van der Walls energy (vdW)+hydrogen bonds+desolvation energy+electrostatic energy $(\mathrm{kcal} / \mathrm{mol})$, B denotes final total internal energy $(\mathrm{kcal} / \mathrm{mol}), \mathrm{C}$ denotes torsional free energy $(\mathrm{kcal} / \mathrm{mol})$, D denotes unbound system's energy ( $\mathrm{kcal} / \mathrm{mol})$.

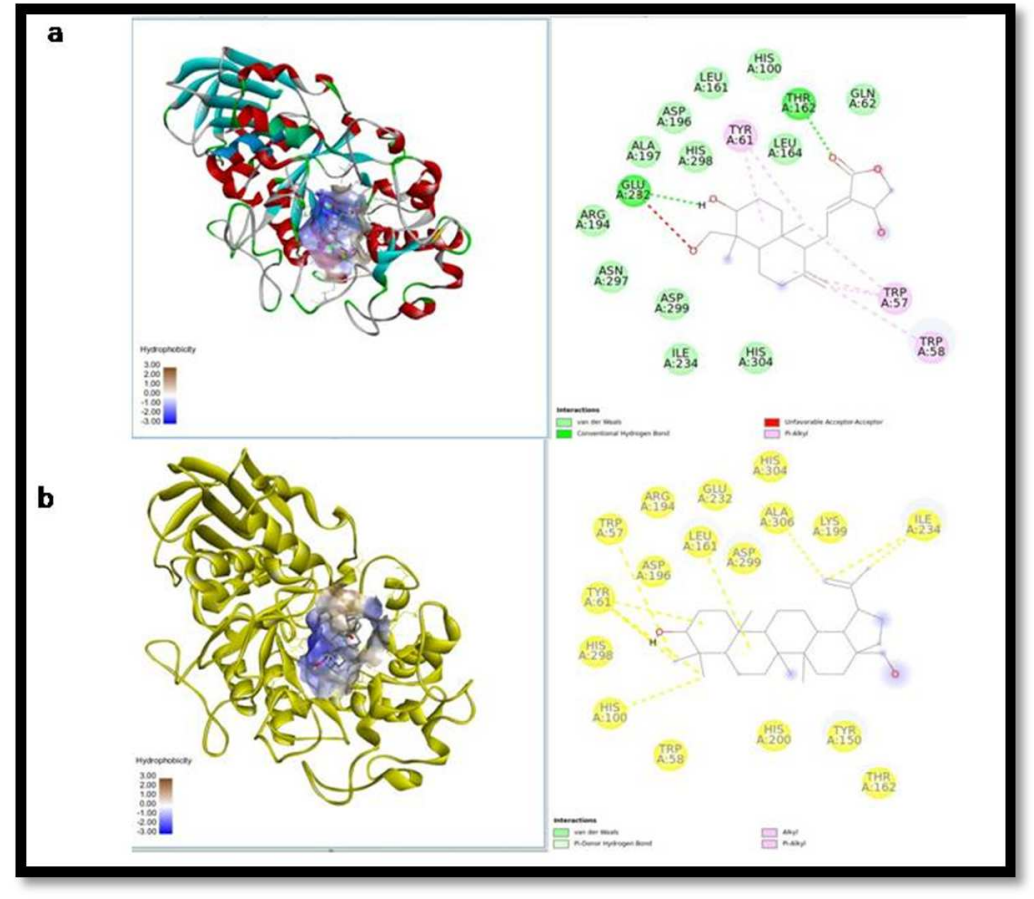

Fig. 11: 3D-schematic interactions pose of amylase with (a) andrographolide and (b) betulin

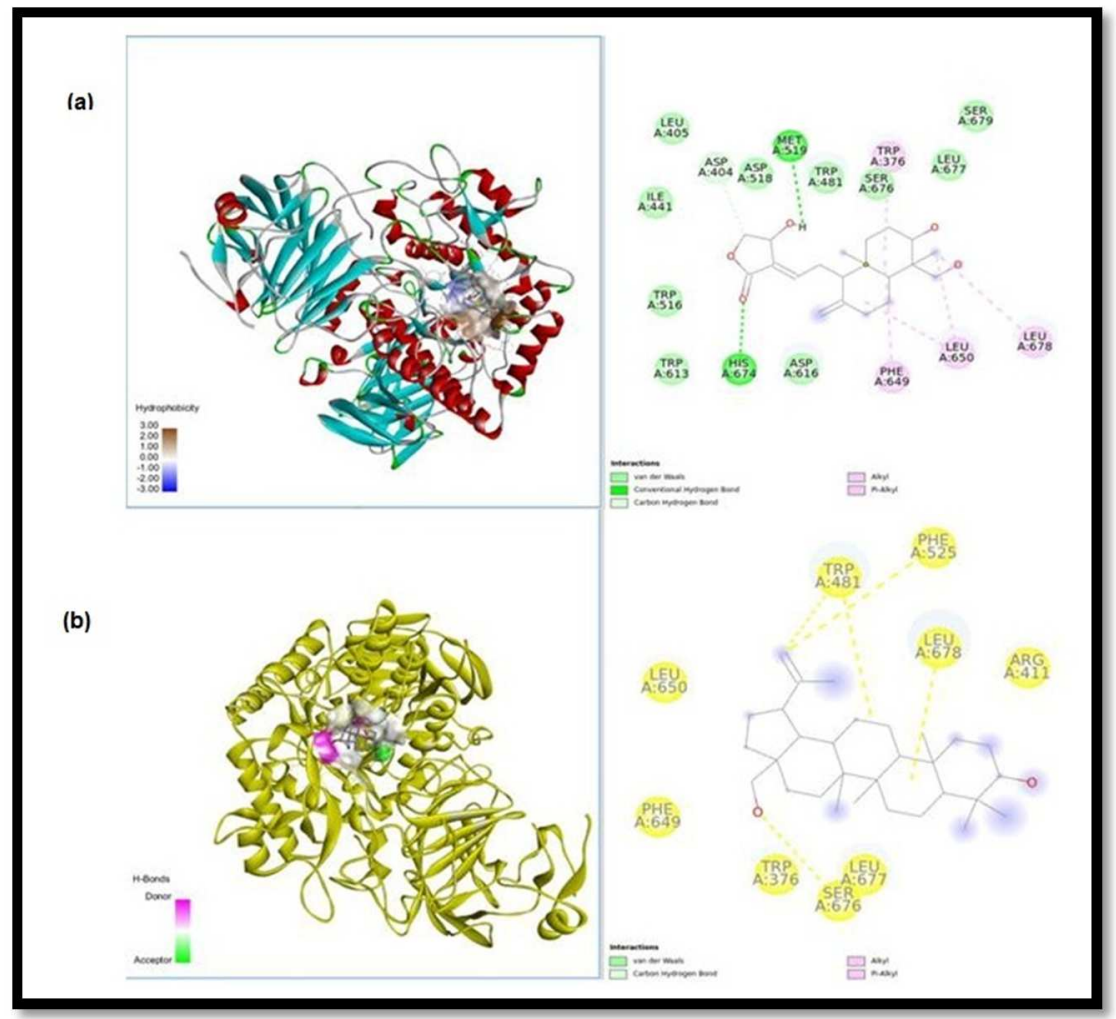

Fig. 12: 3D-schematic interactions pose of glucosidase with (a) andrographolide and (b) betulin 
Table 1: Alpha-amylase and alpha-glucosidase protein with betulin and andrographolide were docked for predicting binding affinity by autodock in MGL tools

\begin{tabular}{|c|c|c|c|c|c|c|c|c|c|}
\hline \multirow[t]{2}{*}{ Protein-ligand } & \multirow[t]{2}{*}{ Compounds } & \multicolumn{8}{|c|}{ Binding energies of the compounds based on their rank (kcal/mol) } \\
\hline & & 1 & 2 & 3 & 4 & 5 & 6 & 7 & 8 \\
\hline Amylase-andrographolide & Andrographolide & -7.9 & -7.9 & -7.8 & -7.5 & -7.5 & -7.5 & -7.4 & -7.1 \\
\hline Amylase-betulin & Betulin & -8.6 & -8.2 & -7.7 & -7.7 & -7.6 & -7.5 & -7.4 & 7.3 \\
\hline Glucosidase-andrographolide & Andrographolide & -7.2 & -6.6 & -6.2 & -6 & -6 & -6 & -5.8 & -5.7 \\
\hline Glucosidase-betulin & Betulin & -5.2 & -5.1 & -4.8 & -4.6 & -4.4 & -4.1 & -3.9 & -3.8 \\
\hline
\end{tabular}

Docking and prediction of binding affinity is presented in table 1. Affinity values predicted was clearly describing the best fit among alpha-amylase and glucosidase. Andrographolide has been showing a binding affinity for amylase: -7.9 and glucosidase e: -7.2 while betulin was showing 8.6 and 5.2 , respectively. Binding affinity among the complex structures was showing the competitive and noncompetitive inhibition method. Mode of interactions is auspicious that hydrogen donor and acceptor playing a vital role and key aspect in molecular rendering. Specific amino acids in the catalytic site are clearly explaining the bonded and non-bonded interaction. Based on the in silico evaluation and stereochemistry binding of the isolated compounds, andrographolide possess potential $\alpha$-amylase and $\alpha$-glucosidase inhibitory excellent binding sites when compared to that of the betulin. This may be attributed due to the differences in the position of the functional groups in the compounds $[29,30]$.

\section{CONCLUSION}

Andrographolide and betulin isolated and characterized from the methanolic leaves extract by using column chromatography and purification were confirmed by high-performance liquid chromatography for the first time reported in this study. In conclusion, the results of the present study clearly demonstrated that Isolated compounds andrographolide and betulin have excellent binding sites and interactions with $\alpha$-amylase and $\alpha$-glucosiade. As a result, it can be concluded that the Isolated Compounds have inhibitory activity against $\alpha$-amylase and $\alpha$-glucosidase enzymes and this therapeutic potentiality could be exploited in the management of postprandial hyperglycemia in the treatment of Type-II diabetes mellitus.

\section{ACKNOWLEDGEMENT}

S. G acknowledges Dr. S. John Britto, Director, Rapinat herbarium, St. Joseph College, Tiruchirappalli, Tamil Nadu for identifying the plants. S. G acknowledges Assistant Professor, DR. L. Cathrine of Holy Cross College, Tiruchirappalli, Tamil Nadu for constant support for this research.

\section{FUNDING}

Nil

\section{AUTHORS CONTRIBUTIONS}

All the authors have contributed equally.

\section{CONFLICTS OF INTERESTS}

The authors declare that they have no conflict of interest. It has not been published elsewhere. That it has not been simultaneously submitted for publication elsewhere. All authors agree to the submission to the journal.

\section{REFERENCES}

1. Grover JK, Yadav S, Vats V. Medicinal plants of India with antidiabetic potential. J Ethnopharmacol 2002;81:81-100.

2. Maurya U, Srivastava S. Traditional Indian herbal medicine used as antipyretic antiulcer, anti-diabetic and anticancer: a review. Int J Res Pharm Chem 2011;1:2231-781.

3. Mahesh AR, Harish K, Ranganath MK, Raviraj Anand D. Detail study on Boerhaavia diffusa plant for its medicinal importance. Res J Pharm Sci 2012;1:28-36.

4. Patel DK, Kumar R, Laloo D, Hemalatha S. Diabetes mellitus: an overview on its pharmacological aspects and reported medicinal plants having antidiabetic activity. Asian Pac J Trop Biomed 2012;2:411-20.

5. Burke JP, Williams K, Narayan KMV, Leibson C, Haffner SM, Stem MP. A population perspective on diabetes prevention: whom should be we target for preventing weight gain? Diabetes Care 2004;26:1999-2004.

6. Krolewski AS, Kosinski EJ, Warram JH. Magnitude and determinants of coronary artery disease in juvenile-onset, insulin-depedent diabetes mellitus. Am J Cardiol 1987;59:750-5.

7. Mathivanan D, Suseem SR. Phytochemical and pharmacological review of Andrographis echiodies. J Chem Pharm Res 2015;7:1167-71.

8. Nirubama K, Rubalakshmi. Bioactive compounds in Andrographis echioides (L.) nees. leaves by GC-MS analysis. Int J Curr Res Biosci Plant Biol 2014;1:92-7.

9. Kanchana N, Rubalakshmi. Phytochemical screening and antimicrobial activity of Andrographis echioides (L.) nees-an indigenous medicinal plant. World J Pharm Pharm Sci 2014;3:702-10

10. Gurupriya S, Cathrine L, Pratheema P, Ramesh J. Isolation and characterization of lupeol from methanolic extract of leaves of Andrographis echioides. Int J Curr Adv Res J 2018;7:11397-402.

11. Gurupriya S, Cathrine L. In vitro antimicrobial activities of (1R,3aR,5aR,5bR,7aR,9S,11aR,11bR,13aR,1 3bR)-3a,5a,5b,8,8, 11a-hexamethyl-1-prop-1-en-2-yl-

$1,2,3,4,5,6,7,7 a, 9,10,11,11 b, 12,13,13 a, 13 b-$

hexadecahydrocyclopenta[a]chrysen-9-ol isolated from the methanolic leaf extract of Andrographis echioides. Int J Biol Pharm Allied Sci 2020;9:1460-71.

12. Zhang Z, Jiang J, Yu P, Zeng X, Larrick JW. Hypoglycemic and beta-cell protective effects of andrographolide analogue for diabetes treatment. J Transl Med 2009;7:62.

13. Subramanian $\mathrm{R}$, Asmawi MZ, Sadikun A. In vitro alphaglucosidase and alpha-amylase enzyme inhibitory effects of Andrographis paniculata extract and andrographolide. Acta Biochim Pol 2008;55:391-8.

14. Lin WY, Lin FH, Sadhasivam S, Savitha S. Antioxidant effects of betulin on porcine chondrocyte behavior in gelatin/C6S/C4S/HA modified tricopolymer scaffold. Mater Sci Eng C 2010;30:597-604.

15. Hetenyi C, Van der Spoel D. Efficient docking of peptides to proteins without prior knowledge of the binding site. Prot Sci 2002;11:1729-37.

16. Deepti R, Sushila R, Permender R, Aakash D, Sheetal A, Dharmender R. HPTLC densitometric quantification of stigmasterol and lupeol from Ficus religiosa. Arab J Chem 2015;8:366-71.

17. Jain PS, Bari SB. Isolation of lupeol, stigmasterol and campesterol from petroleum ether extract of woody stem of Wrightia tinctoria. Asian J Plant Sci 2010;9:163-7.

18. Amal K Maji, Niladri Maity, Pratim Banerji, Debdulal Banerjee. Validated RP-HPLC-UV method for the determination of betulin in asteracantha longifolia (L) nees. extract. Int J Phytomed 2013;5:131-15.

19. Himanshu Joshi, Gyanendra Kumar Saxena, Vikas Singh, Ekta Arya, Rahul Pratap Singh. Phytochemical investigation, isolation and characterization of betulin from bark of Betula Utilis. J Pharmacogn Phytochem 2013;2:145-51.

20. Shuang T, Wang JX, Zheng XJ. Simple synthesis of allobetulin, 28-oxyallobetulin from betulin and betulinic acid. J Chem Soc 1998;1:3957-65. 
21. Zhang S, Kumar K, Jiang X. DOVIS: an implementation for high throughput virtual ending using autodock. BMC Bioinform 2008;9:126-8.

22. Madeswaran A, Umamaheswari $\mathrm{M}$, Asokkumar $\mathrm{K}$, Sivashanmugam T, Subhadradevi V, Jagannath P. Computational drug design of potential $\alpha$-amylase inhibitors using some commercially available flavonoids. Bangladesh J Pharmacol 2014;9:72-6.

23. Burgos RA, Caballero EE, Sanchez NS, Schroeder RA, Wikman GK, Hancke JL. Testicular toxicity assessment of Andrographis paniculata dried extract in rats. J Ethnopharmacol 1997;58:219-24.

24. Koteswara Rao Y, Vimalamma G, Rao CV, Tzeng YM. Flavonoids and andrographolides from Andrographis paniculata. Phytochemistry 2004;65:2317-21.

25. Du Q, Jerz G, Winterhalter P. Separation of andrographolide and neoandrographolide from the leaves of Andrographis paniculata using high-speed counter-current chromatography. J Chromatogr A 2003;984:147-51.

26. Soica C, Dehelean C, Danciu C. Betulin complex in c-cyclodextrin derivatives: properties and antineoplasic activities in vitro and in vivo tumor models. Int J Mol Sci 2012;13:14992-5011.

27. Siddiqui S, Hafeez F, Begum S, Siddiqui B, Oleanderol S. A new pentacyclic triterpene from the leaves of nerium oleander. J Nat Prod 1988;51:229-33.

28. Mahato SB, Kundu AP. ${ }^{13} \mathrm{C}$-NMR spectra of pentacyclic triterpenoids-a compilation and some salient features. Phytochemistry 1994;37:1517-75.

29. Madeswaran A, Umamaheswari $M$, Asokkumar $K$, Sivashanmugam T, Subhadradevi V, Jagannath P. Computational drug discovery of potential aldose reductase inhibitors using in silico studies. Elect J Biol 2012;8:67-72.

30. Dias R, Azevedo WF. Molecular docking algorithms. Curr Drug Targets 2008;9:1040-7. 